\title{
Globalization and Emerging Governance Modalities
}

\author{
Deane Edward NEUBAUER ${ }^{1}$ \\ ${ }^{I}$ Globalization Research Network, University of Hawaii, Manoa
}

\begin{abstract}
This paper explores the possibilities for global governance effectively dealing with the international transmission of disease. First, zoonotic regulation and control pose a special case for public health agencies, and this paper proposes a propositional model for an effective public health stance. Second, globalization dynamics are briefly reviewed in terms of an emerging consensus on the need for global governance in public health. Third, a brief examination of global governance modalities suggests that a strong global governance case has distinct limitations (despite its possible justification); an exploration of contemporary directions in global governance follows. Finally, the paper examines the phenomenon of contemporary zoonotic control within the conditions of an effective regulatory regime.
\end{abstract}

Key words: global governance, international transmission of disease, control of zoonoses, public health, effective regime

\section{Introduction}

The global governance of zoonoses presents a special case for global public health. The structural framework and dynamics of public health define the parameters of how emerging mechanisms of global governance are likely to influence the control of zoonoses. I begin this paper with a review of some of the endemic tensions that exist within efforts to extend public health into a global framework. I then discuss how the dynamics of contemporary globalization influence the transformation of both social and governmental behavior. I review the notion of "regimes" of governance that embrace trans-national and supra national entities. Finally, I inquire about the conditions for an effective regime for zoonoses control via global governance.

\section{Part One: The Structural Tensions of Public Health}

Efforts to control infectious disease lie within the writ of state authority and are bound by the framework of public health. Wherever society has legitimized private capital as to some degree separate from that of the state, a structural tension exists between the state's interest in defining health on behalf of its subject population, and the resulting regulation of private inter-

Received Feb. 23, 2005/Accepted May 9, 2005

Reprint requests to: Deane Edward NEUBAUER

3454 Oahu Ave., Honolulu, Hawaii 96822

TEL: +1(808)956-9781, FAX: +1(808) 956-9431

URL: www.globalgrn.org ests. When the state does not permit the existence of private capital within a framework of civil society (and the structure of rights implied), national state structures pursue public health as part of their collective national responsibility.

This structural tension with private interests in the context of global governance informs zoonoses because (a) the processes of contemporary globalization are changing accepted notions of the role of the state (of which more later), and (b) scholars of public health have increasingly come to recognize that the definition of health itself (which the state must act to protect and promote) is flexible, constantly changing, and subject to the transformations occurring in modern, globalized consumer societies (1). Indeed, a review of competing definitions of public health by the Institute of Medicine (IOM) in the United States in 1988 led the IOM to define public health as "fulfilling society's interest in assuring conditions in which people can be healthy" (2). This broad definition, were it to be taken seriously and public policy aligned with it, would create a politics in which state power potentially could invade every private activity that challenges health. Pursued with vigor the political power of the state could develop into a national "health police".

The proposition that the state should regulate directly the "upstream" causes of health/disease is advocated by 'the social production of disease' school ${ }^{1}$ and is opposed by those concerned that pursuing public health with such means will lead to excessive state regulation of private interests. Ticklish

${ }^{1}$ Exemplified for example by Evans, et al. (4). 
regulatory issues are also raised by the so-called new public health in which individuals are held to be primarily responsible for their own health. In the latter regulatory regime, responsibility shifts from the state (e.g. to regulate noxious industries) to the individual (e.g. to take responsibility in avoiding the products of noxious industry.) The regulation of smoking falls very much within this paradigm. Current controversy over eating behaviors, resulting obesity, and the impact on the "public's" health are of the same character, as are efforts to hold mothers criminally responsible for ingesting "dangerous" substances during pregnancy (ranging from methamphetamines to alcohol and tobacco). As political scientists look at these issues, health as a value always stands in dynamic tension to other rights and values (e.g. wealth, liberty, rectitude, etc.) What societies negotiate at any given moment is the relative authority to be given one value weighed against another. The ultimate policy questions become how much authority will health values and those who espouse and affect them have in society, and at the opportunity cost of what else (3)?

Two oft-conflicting notions of authority contend within the contemporary public health paradigm. Optimizing the public's health in a world of expanding threats requires increased amounts of state intervention. However, in part because of the prospect of this increasing state intervention, and to side-step the challenge to the power of private interests associated with the creation of dangers to the public's health, some would shift the ground for responsibility for health to individuals, who would be required to take on new responsibilities to calibrate their social behaviors (where to go, where not to go, what to eat, what not to eat) to promote their own health.

Public health always involves some construction of "the public" and its presumptive interests as defined by state authority. Public authority over the monitoring and control of historic zoonoses has involved a full range of extensions authority of state authority to those areas from which such disease arises. And, while some of these extensions are well established, others reappear in response to changing social demands and technologies. As new diseases emerge, each simultaneously is "fitted" into the prevailing model of regulation, even as they challenge that application. National and transnational regulation of beef herds under threat of a BSE infection is a case in point. Equally important, however, has been the level of state fiscal support for public health. Even as the dynamics of globalization increase health threats to the public, the prevailing ideology of neo-liberalism through which state policy is filtered leads to a diminution of state authority and diminished resources for public health disease control (5).

\section{Part Two: The requirements for effective public health}

The goal of global governance of zoonoses lies in creating an effective regime of regulation. Below I will examine the notion of global regulatory regimes. Here, I seek to determine where in our understandings of public health as a regime of national regulation we find the necessary properties to be effective. The core argument is that a global governance regime of zoonoses regulation would need to be modeled on these characteristics.

\section{Proposition One: Good public health depends on effective public policy}

This seemingly self-evident proposition conceals a greater subtlety, for the current regime of globalization has relied on the state and its capacity to effect purposeful public health policy. Indeed, political scientists will categorize states as weak or strong in part by their ability to create and maintain effective policy processes. Weak states can create, but not necessarily implement public policy (6). Much of the world continues to live in "weak" states in which governments (central as well as regional and local) have difficulties ranging from grave to impossible to carry out policy intentions, particularly those regarding public health ${ }^{2}$. In these circumstances, maintaining good public health becomes impossible.

\section{Proposition Two: Effective public health is dependent on sufficient social investment}

Overall, public health is losing comparative budget parity with the rising costs of curative medicine in the developed nations. In the United States, with overall medical costs once gain breaking out into double digit annual increases, the relative share of national budgets devoted to public health declines. Especially in times of economic downturn, and the absence of compelling crisis conditions, social investment in public health is uncertain in most national budgets.

\section{Proposition Three: Sufficient social investment is dependent on prevailing political and economic ideology}

Neo-liberal economic and political ideology call for reduced taxes, a dismantling of welfare state structures, increased individual responsibility for social consumption, deregulation of the private sector, and reduced governmental spending. Those who see global public health structures as incapable of meeting the public health challenges spawned by globalization, find the major culprit in neo-liberal policies weakening the public sector (7). Adoption of necessary regulatory regimes may be viewed as a kind of social investment. The unwillingness of the U.S. and China to participate in Kyoto for the reason that to do so would threaten continued levels of economic development is a testament to the power of neo-liberalism. The endorsement of the protocols by Russia this week (in addition to the relative advantage this gives Russia within the accord group) is a measure of its relative irrelevance to the current politics and economics of Russia.

Proposition Four: Inequality is detrimental to good public health

A growing consensus holds that contemporary globalization is increasing inequality. A long-range macro analysis of inequality and health status holds that as inequality declines, overall levels of health improve, and the reverse (8).

\section{Proposition Five: Regime corruption is detrimental to good public health}

Regime corruption manifests itself when particularized

\footnotetext{
${ }^{2}$ Even strong states experience complex inabilities to enforce problematic policies. Common examples would include prohibition and contemporary drug laws in the U.S.
} 
interests subvert public policy for their own benefit. Persistent regime corruption diverts public policy from its intended purposes. It follows that public health's successes or levels of regime corruption significantly determine failures.

\section{Proposition Six: Good public health is directly linked to positive social, economic, and political development}

Uneven or ineffective development results in poverty and weak regime states. The 'social determinants of health' school holds, importantly, that good developmental policies contribute more overall to the health of the public than medically oriented individual intervention, no matter how sophisticated and successful the latter. Good development policies lead to improved population health; uneven and unsuccessful development leads to inequality, poverty, and deficient provision of clean water, effective sanitation, adequate shelter and diet, as well as the political problems that follow from these conditions ${ }^{3}$.

\section{Proposition Seven: To achieve policy success, public health needs to be able to value its own successes}

The overall goal of public health is to reduce or eliminate the incidence of specific diseases. When public health practices result in lessened disease threats, the relative value of public health in the policy process wanes. In an odd way, public health is successful when things don't happen, when people do not become ill; it is about negative instances, which are notoriously difficult to "count". Tying this observation to proposition two above, public health's budgetary fates rise during times of crisis and suffer during times of normality (9).

\section{Proposition Eight: Public health suffers from the politics of focused expertise and technology}

In a related manner, public health funding tends to lose out when public policy is oriented toward producing focused expertise and technology. Public sector investment in "health" has reached very high levels: the National Institutes of Health in the United States received \$27,066,782,000 in FY2003. These massive levels of investment have produced spectacular successes in knowledge creation, the invention of non-invasive and minimally invasive surveillance of the body, and a vast array of medical interventions. At the system level, however, the multiplication and diffusion of highly technologized interventions results in rising expectations for medical care, and increased overall medical care costs, which crowd public health spending in national and sub-national budgets.

By contrast much important public health work is low tech. In a corollary to Gresham's law, high tech drives out low tech in budget contests (just as specialized medicine trumps primary care, and cutting edge proprietary pharmaceuticals trump generics). Some exceptions to this proposition may exist

\footnotetext{
${ }^{3}$ The 1999 UNDP estimates that 1.2 billion people live in absolute poverty. An equal number do not have clean water. Almost a billion people are malnourished; more than 850 million remain illiterate. UNDP, 1999, UNHABITAT, 2003. After three decades of intense globalization-driven development, approximately a fifth of the world's population live in failed survival conditions. Even minimally successful public health is difficult if not impossible under these conditions.
}

with emerging tools for micro surveillance devices.

\section{Proposition Nine: Achieving public health is a moving target:} notions of acceptable levels of health change over time; new diseases are constantly developing

Health is a relative value. Achieving it is an uncertain objective. Potentially the demand for health-especially as defined by medical interventions - may be infinite in a social climate in which individuals seek and receive new interventions to extend life or improve some aspect of bodily well being (10). These observations clash with the languages and perspectives of the policy process in which notions of attacking problems, defeating social ills, or achieving victory in another war on something are commonplace. These rhetorical tropes serve well-recognized strategic and tactical means within the policy processes for mobilizing support, achieving agenda positions, and gaining budgetary allocations. When applied to public health, however, they create unrealistic notions of what can and cannot be accomplished within the frame of health by those practices we term public health. The result is that rhetorically, we are always in some ways losing the public health battle (11, 12).

My hypothesis is that any regime of zoonotic control will be subject as well to all of these propositions. Whatever governance regime is developed for zoonotic control at whatever level (local, regional, national, global), the effectiveness of such controls will depend on the degree to which the values and institutional practices suggested by these propositions is found to apply.

\section{Part Three: Dynamics and Impacts of Globalization}

The contemporary era of globalization dates from the mid-1960's. A set of similar global transformations took place during the period 1870-1914. In both cases heightened economic integration resulted from increases in international trade, finance, and investment. While this earlier globalization took place within the framework of the national state, contemporary globalization has expanded beyond the nation state through transnational economic actors, multinational corporations. The result has been to create a new political space within which the immense transactions of the global economy take place. While new economic institutions have developed in contemporary globalization, corresponding political governance has not: economic space has expanded beyond political space $(13,14)$.

The dynamics of contemporary globalization compress time and space, creating a more immediately available world of goods, services, communications and interactions of all kinds (including military) (15). Massive amounts of capital are aggregated at the global level, circulating in currency flows that dwarf anything previously known. These capital concentrations provide immense power to private capital to transform societies, often at the expense of a relative reduction in the power and authority of national governments, who in comparative terms lose the capacity to control their own policy agendas (14). Economic interdependence brings unparalleled efficiencies in goods and information exchanges, but at the price of a 
hyper-sensitivity to negative economic effects within the system, as the 1997 Asian currency crisis revealed. Sudden disease outbreaks such as SARS can also have large and immediate negative economic effects that rapidly ripple throughout the system. The actual collapse of national economies from global financial instability such as that of Indonesia in 1997-98 can drastically reduce national income, with society-wide negative health consequences ${ }^{4}$.

Contemporary globalization, operating through its primary vehicle the multinational corporation, shifted the manufacturing centers of the world into the former developing world. Essential to the success of this relocation has been the creation of constantly innovating transportation and communication systems that move goods with steadily increasing rapidity and lowering costs, and a global information system based on constantly innovating communications technology and computer networks (16). As is well known, these advances enhance the spread of disease throughout the world and vastly complicate efforts to establish effective controls.

We are just beginning to glimpse how changes in the ownership and extension of global media are coupling with other elements of our information societies and their networking capacities. Already it is obvious that basic consumption patterns related to health are changing, as societies become more consumer oriented. Changes in diet, work and living patterns are associated with goods through which we fashion our identities and make choices. Castells, like Harvey, sees the rate and nature of change the central element of how globalization impacts society, a process that he calls the creation of network societies. This contemporary process of change has the apparent property of being high recursive; elements of change in one dimension affect another through chains of reciprocal causation, working themselves back to the initial causal elements and producing new, and often unexpected, effects in the process. Social theorists make strong analogies to how ecological systems function recursively in making these operations. When these new and complex recursive processes occur within the social stew of hyper-urbanization, the outcomes are highly unpredictable (17).

Globalization is also marked by new means of wealth creation and distribution, inducing labor forces to move toward aggregations of capital most of which are urban. This process has touched off the largest migration in human history (18). The 21 st century has become the urban century as for the first time in human history more people live in cities than in rural areas. One component of this migration is cross-border, legal and illegal migrants seeking work. This pattern, however, is dwarfed by within-country migrations which have brought hundreds of millions of people into cities, now perceived as the critical nodes of global production, and therefore the locus of jobs. In many of these cities, especially the "newly large" cities of the developing world, or the mega-cities of Asia, living and working conditions resemble those of Dickensian England. At the current edge of the 21 st century's world, industrialism

\footnotetext{
${ }^{4}$ Health can also be viewed in a broader sense, as when national economic collapse threatens social order allowing civil unrest to erupt with widespread loss of life.
}

coupled with urbanization has reproduced the social conditions of the 19th century. The unchecked growth of mega cities as survival harbors make them the new reservoirs for the lethal combination of poverty, crowding, insufficient sanitation, impure water and disease.

The non-urban world has also been fundamentally transformed, as logging, mineral extraction, and oil exploration and production have brought virtually every hectare of global space under the economic gaze of capital exploitation. In search of ever greater food supplies, fisheries throughout the world have been driven to collapse and forests pushed back for agricultural development, especially when monoculture drives out smaller scale diversified agriculture. The agricultural equivalent to global financial interdependence lies in the possibility of irreversible environmental shifts such as drought in China, which under current financial arrangements could cause market forces to eliminate from global demand those who cannot afford grain. Structural inequalities coupled with civil unrest (another kind of inequality) already produce widespread hunger, malnourishment and famine. An environmental disaster in a large population, most obviously China or India, could have devastating effects within the world system. This, of course, is the great fear environmentalists have for dependence on mono-cropping, species loss, and water management ${ }^{5}$.

In sum: contemporary globalization has dramatically increased global wealth, through innovation and joining new capital to massive labor forces; it has also produced a distribution system that promotes inequality on a scale previously unseen. Stunning innovations in productive capacity, communication, and transportation have imposed new technologies throughout the world. World populations have increased in number and concentration as the world has rapidly urbanized; ecological imbalances have been intensified and with them the conditions for the spawning and transmission of new diseases increased. Contemporary patterns of global industrialization create profound ecological challenges from resource depletion.

One further note on globalization as a market phenomenon. Contrary to traditional theories of economics, the market is not self-governing. Classical and neo-classical economics can assure us that markets will create efficient price levels and send appropriate signals to organize supply and demand, but markets also routinely produce externalities, sometimes of massive, negative proportions, and are inseparable from the business cycle. As global wealth increases, the business cycle produces spectacular wealth during periods of boom and spectacular poverty and despair during periods of bust: the greater the extent and interdependence of the world system, the greater the attenuation of these extremes.

In the industrial progression of national economies, the early periods of raw industrial growth were followed by the imposition of regulatory regimes designed to mitigate the human costs of industrial development. Markets may be efficient for exchanging goods, but they are not effective in representing the controls on excess that modern industrial human populations historically have come to demand from the

\footnotetext{
${ }^{5}$ Vietnam's concerns for China's proposals to dam portions of the Mekong River headwater system are a case in point.
} 
economic schemes within their societies. The replication of these economic excesses at the global level is producing similar movements toward global governance (regulation). In a world still governed by the sovereignty of nation states, however, achieving the required and effective regulation is a daunting challenge.

\section{Part Four: Governance regimes: Strong and weak programs of global governance}

The compelling questions for global governance are what should be governed and how? The fundamental environmental/ bio-health questions for global governance include: whether to seek remedies eliminating the causes of negative health and environmental outcomes; or to pursue limited programs that seek to mitigate effects at the margin.

A similar tension exists within the discourse of global governance: should global governance seek to regulate the processes of globalization themselves, or should efforts concentrate on regulating effects? While the two can be seen as opposite sides of the same coin, these can fairly be termed the strong and weak programs of global governance.

The strong program envisions institutions that have a direct capacity for regulating (with sanctions) individual actors, whether they are nations acting on behalf of private interests (or their own state corporations), or private interests, and individual actors themselves. The weak case envisions governance mechanisms that operate largely through existing institutions (including states) and require their compliance to effect action. These positions define the antipodes of a governance continuum. The current politics of global governance distributes advocacy for various structures or mechanisms along this continuum.

Obviously, the strong governance program most directly addresses the operation of globalization actors at the transnational level; conversely, this position acknowledges the degree to which state sovereignty has already been compromised by cross border globalization (14). A propensity for the strong program in large part depends on one's view of the global condition. If it is seen as a "ticking time bomb" e.g. unrelenting global warming with catastrophic consequences such as the possible melting of the Ross ice shelf and rising sea levels, one views the world in crisis and moves toward a discourse that promotes more radical changes necessary to sustain society under threat. The scale of the threat, it would be argued, justifies actions that impinge drastically on the traditional institutions of the state and its sovereignty. A paradigmatic example may be the Montreal treaty on CFC regulation.

The biological version of this scenario might be a conviction that current global practices previous mirror conditions in human history that led to the emergence of new diseases or their epidemic spread: a warming climate, the rapid and large scale movement of populations, novel mechanisms of transportation that permit rapid communication of peoples, and destruction of existing barriers between native forests, agricultural land, urban concentrations, and compromised water and sanitation systems (19). Convinced of this scenario, one might seek to impel regulatory settlements intended to reduce population flows into cities, reduce the destruction of forests by agricultural incur- sion, curtail global warming, etc., actions that could only take place by directly interdicting the economic forces creating them.

But such measures are unlikely. Policy processes do not work that way. Crises discourse may serve to modify the content of policy talk, but for large scale regulatory efforts to take place, the catastrophe in whose name such actions are taken must already have occurred. People are only convinced of the severity of truly profound crises until their very occurrence has validated that severity. The purpose of crisis dynamics and its role in the strong governance program is to legitimize lesser efforts. It is in this terrain that global governance is emerging.

Within weak programs for global governance two basic types prevail; one seeks to reform existing institutions of global governance, the other to fashion novel regulatory regimes.

Nayyar and Court indicate the assumptional base of the reform model:

The endeavor should be to make the market-driven process of globalization conducive to a more egalitarian and broadbased development pattern. The object of such a design should be to provide more countries with opportunities to improve their development prospects and more people within these countries to improve their living conditions. It would have to be supported by a new institutional set-up. This would mean providing global public goods, such as world peace and a sustainable environment, as well as regulating global public bads, such as international crime whether trade in drugs, arms, people, or [human] organs. It will be necessary to reform existing institutions and to introduce new rules or create new institutions. Some of these would require a system to correct for the failures of unregulated or liberalized international markets, while other initiatives will be needed to build up missing markets (14).

From this proposal spring reforms of existing governance institutions including the United Nations ${ }^{6}$, the International Monetary Fund, the World Bank, and the World Trade Organization. Nayyar and Court are sensitive to the needs for differential application of regulatory rules for countries at different levels of development, for the need to make global governance more inclusive (and not just a rich nation's club), to provide a voice for those currently excluded, and to specify the conditions under which countries can opt out or exit from multi-lateral rules. Their reforms include the desirability for articulating the obligations of transnational corporations as well as their rights, including some version of an international regime of antitrust $^{7}$. Like similar global governance proposals, acknowledgement is made of existing institutions that already constitute core arrangements of governance on which this larger program could be built, e.g. UNCTC, UNCTAD, the Organization for

\footnotetext{
${ }^{6}$ The major reforms proposed are designed to restore the weakened moral authority of the UN: reforming the Security Council by expanding membership to acknowledge the changed political economic realities of the current era and limiting veto powers of members; developing a model of independent funding, creating a mechanism for the rapid assembly and dispatch of a volunteer peace force; creating a global people's assembly on principles more democratic than those of the General Assembly; and creating an economic analogue to the Security Council, an economic security council (13).

${ }^{7}$ For a broader discussion of democratizing global governance (20).
} 
Economic Cooperation and Development (OECD), the International Finance Corporation (IFC), and the International Centre for Settlement of Investment Disputes (ICSID).

The regime approach to global governance seeks to identify the existence of these institutions and practices in relation to specific problems they would regulate. Oran Young defines regimes as "sets of rules, decision-making procedures, and programs that define social practices, assign roles to the participants in these practices, and govern their interactions" (21).

Regimes differ in terms of their functional scope, geographical domain, and membership. Regimes are empirical, and may be unstable; they form in response to some situations and not others. Regimes have proliferated within environmental governance largely in response to discrete issues. Examples would include the Great Lakes water quality regime, the Antarctic Treaty System, and the European transboundary air pollution regime.

Regimes may be nested in larger institutional structures, e.g. that for high seas fishing, which is subject to the more encompassing law of the sea. Often regimes are "lightly administered", generating compliance with minimal organizational resources ("governance without government"). While regimes often do not seek to provide comprehensive systems of public order for large geographic regions, they may occasion participation by states as well as inter-governmental actors. The result, Young suggests, is that regimes tend to form horizontally rather than vertically; they represent a "complex pattern of decentralized order." (21)

Since its inception in 1946 and consistent with its predecessor organizational versions, the WHO has ascribed to the weak regulatory program, utilizing the terms employed in this section. Its constitutional function is the direction and coordination of international health work, including setting international norms and standards for health, and technical cooperation among members. Evidence of its weak program nature can be seen in those instances in which it has abjured political involvement (especially concerning Eastern Bloc membership issues in the 1960's) (22). An issue beyond the immediate scope of this paper is the examination of current efforts within WHO to ascertain those that are part of regime formation and implementation, a la Young.

\section{Part Five: Globalization Dynamics, Global Governance and Zoonoses}

In an effort to apply these diverse observations about public health, global governance and globalization, I turn to Frederick Murphy's 1998 presentation of emerging zoonoses in the special issue of the journal by the same name. I choose Murphy as a text because of his effort to capture in this brief review not only the range of factors implicated in emerging zoonoses, and the specifics of the most prevalent instances of that date, but also because he focuses on specific proposals to address what he sees as the need for an effective response. I seek to put this conclusion in the context developed in this essay.

"...an emerging zoonosis is 'a zoonosis that is newly recognized or newly evolved, or that has occurred previously but shows an increase in incidence or expansion in geographical, host or vector range'. Emerging zoonotic diseases have potentially serious human health and economic impacts and their current upward trends are likely to continue." Examples include: avian influenza, Bovine Spongiform Encephalitis (BSE) and the Nipah virus (23).

Writing before the emergence of SARS, but in the context of BSE in the UK, HIV/AIDS, Sin Nombre and West Nile Virus, Murphy's specific concern is the adoption of "unique strategies" that will build more on fundamental research than "traditional" approaches. Included will be the rebuilding of "a cadre of career-committed professionals with a holistic appreciation of several medical and biologic sciences" (5).

He sees a persistent and to some extent alarming increase in emerging disease episodes (nearly all of which involve zoonotic or species-jumping infectious agents) including at the microbial/virologic determinant level mutation, natural selection, and evolutionary progression.

Among individual host determinants he identifies acquired immunity and physiologic factors. Host population determinants include host behavioral characteristics and numbers as well as societal, transport, commercial, and iatrogenic factors. Environmental determinants include ecological and climatologic influences.

The remainder of his review focuses on ecologic factors, especially those exemplified by arbovirus diseases. He seeks to identify lessons learned from Venezuelan equine encephalitis epidemics, the equine morbillivirus outbreak in Australia, from Ebola hemorrhagic fever, rabies epidemics, from the hantavirus pulmonary syndrome epidemic and from bovine spongiform encephalopathy in cattle and new-variant Creutzfeldt-Jakob disease in humans.

Murphy's policy argument is to extend the discovery-tocontrol continuum to the full range of zoonotic diseases. The discovery-to-control structure draws on elements from fundamental scientific research, to the creation of an effective practitioner community, to creating and sharing data bases drawn from increased national and sub-national surveillance, to the full range of actions required in the final control stages of zoonotic diseases. And at each step, he is sensitive to their costs (without necessarily employing the various languages of public policy that apply). He recognizes the extensive nature of the final phases of the project.

More expensive and specialized expertise and resources come into play in the final phases of the discovery-to-control continuum: public health systems, including rapid casereporting systems, surveillance systems, vital records and disease registers, staffing and staff support, logistic support, legislation and regulation, and expanded administration; special clinical systems, including isolation of cases, quarantine, and patient care; and public infrastructure systems, including sanitation and sewerage, safe food and water supplies, and reservoir host and vector control.

My interest in Murphy's review and analysis stems precisely from its initial assumption that the beginning point for eventual control begins with discovery. It certainly seems a reasonable place to begin with. However, most of the above 
argument about globalization suggests, paradoxically, otherwise. That argument says, in effect, that if we continue along the road that globalization is taking us, we may be "producing" diseases in ways that overwhelm the capacity of systems to deal with them if they are actuated at the point of discovery.

Is this a silly way to reason? I don't think so. Defining zoonoses in terms of a set of problems within the discovery-tocontrol continuum is analogous to the weak program for global governance. It accepts the premise that important public health situations constitute problems to be solved by intense, expert, scientific driven problem solving techniques.

But these issues may more rightly be dilemmas than problems. A dilemma differs from a problem in that the situation it "contains" will not produce a "solution" at the level of analysis at which it stated. Simply: within a dilemma one cannot continue to do what one is doing - the thing that produces the "problem" - and gain an effective solution. In the above analysis, the world cannot continue to embrace and support the activities of contemporary globalization and meet the public health problems it will create. To resolve the dilemmas that constitute global public health requires changing (perhaps in radical ways) the ways that globalization works, so that it will produce different results. Problems say: do more; dilemmas say: do something different.

This is what proposals for global governance purport to do. The all-important question is, even were they to succeed, through the reforms proposed, would these be sufficient to create transformations in globalization behavior yielding different outcomes? One should never say never. I am tempted to argue, nevertheless, that we cannot solve the problem of creating an effective regime of zoonotic control because such a regime, as posited, would not change the conditions of the global economy that are producing the very diseases one wants to control.

This does not mean however, that one might not embrace projects or obtain results that are important steps in this direction. For example, I have made much of the tension between the current world of infectious disease in which there is a large, and perhaps ever increasing, need for more research, more science, more data bases, more trained personnel and international cooperation on policy implementation, all of which cost money (and involve additional contribution of resources on the part of the state), and the trend under current globalized regimes of neo-liberalism to actually weaken the state, to shrink public spending and to weaken its regulatory hold. Following this logic suggests to me two conclusions.

One, we will fall behind in the kind of program Murphy advocates because the political and economic forces that promote global neo-liberalism are stronger than those that promote public health (including zoonoses control). In the contest of values and public policy discussed in section one of this paper, particularized interest will triumph over more generalized interests. Two, some disease will present itself with such threat and virulence that its consequences to existing society cannot be ignored. In the face of this manifest crisis (perhaps a breakout of the current Thai-based avian flu virus), public health intervention will go to the top of the policy list. Not only public monies will be made available, but also private sector funds. William Gates or Warren Buffet, or George Soros or some other combination of the world's largest holders of private wealth may seek to intervene to transform the direction of current public policy. And that might turn the tide on the existing threat.

Or not. Within the last century only the flu pandemic of 1918-19 has constituted as great and widespread a threat to human population as the HIV/AIDS pandemic. Yet threats of this magnitude have failed to mobilize an effective interventionist regime. While it is useful to speculate on some of the reasons that such a regime has not emerged (e.g. the disease emerged outside the developed world (non "us"), and then proliferated in stigmatized populations, wide spread denial of the size and extent of the disease by many governments, etc.) the combination of urgency of impact (disease incidence continues to rise) and failures in the establishment of an effective governance regime (typified by the failure of the U.S. government to contribute its full share to the global fund) shows that the HIV/AIDS pandemic has new lessons for us about how crisis dynamics do and do not work to effect appropriate responses.

Before proceeding to a conclusion, two final words. On risk. Like health, risk is a socially constructed category that changes within the complex norms and values of a given society or culture. What is an acceptable level of risk at one period of time, may not be in another; what is an acceptable level of risk for one group (e.g. others), may not be for another (e.g. ourselves) ${ }^{8}$. Notions of risk are negotiated within the political process; notions of crises, their relative severity and the amounts of resources to be devoted to them emerge from the complex processes of bargaining within the political process. When the site of the political process is global, rather than national, and when the mechanisms for decision making lack the force of national sovereignty, the complex calibrations of acceptable risk compound exponentially.

On technology. We are wise enough to realize that technology can bring astonishing immediate benefits, but also through unexpected recursive feedback loops, create yet new and unanticipated problems, perhaps as severe as those they were designed to fix. Nevertheless, at the very least microtechnology and nano-technology hold enormous promise for assisting with surveillance tasks to control disease spread. Biobased sensors that can be made cheaply and sensitive down to the individual molecule level promise new ways of scanning large numbers of people (e.g. airport arrivals) cheaply and with minimal intrusiveness. Nano-tech sensors operating within the bodies of suspected infectious persons are also being studied. To see the individual as the broadcasting site for disease surveillance strikes many as a further draconian incursion into the oppression of individual liberty...but to return to our

\footnotetext{
8 "The question of acceptable standards of risk is part of the question of acceptable standards of living and acceptable standards of morality and decency, and there is no way of talking seriously about the risk aspect while evading the task of analyzing the cultural system in which the other standards are formed (24). My position is that what Douglas terms the "cultural system" includes the political process through which notions of acceptable risk are translated into public policy and resource allocations.
} 
opening theme, this tension between private interest (including the self) and the public's health is endemic.

\section{Conclusion}

This is not a pessimistic paper, although it may read like one. It makes a simple argument. Globalization is about the deployment of capital throughout the world through marketprivileging mechanisms. Globalization has a powerful up side in the vast wealth that has been created through its mechanisms, and the benefits that it brings to millions of people every day. (The World Bank for example estimates that 400 million people in China have been lifted from poverty by the mechanisms of the current capitalist based society.) But globalization also has its dark side, some of which is eluded to above, and which can be easily amplified in reference to the millions throughout the world who work in conditions that are unregulated, dangerous and underpaid ${ }^{9}$; to the emergence of a world-wide sex industry tied to human trafficking that acts as a particularized HIV/AIDS reservoir; to the wanton disregard of private enterprises in many parts of the world to environmental destruction; to corruption and theft in the higher levels of some of the largest corporations in the world, global trafficking in arms and drugs, etc. ${ }^{10}$

My argument is in the end simple: the dynamics of globalization have become the major "factor" in the social production of disease, including those elements that are intimately associated with the emergence of zoonoses. Directly addressing how these globalization dynamics impact human populations to produce disease must be a program for global governance ${ }^{11}$. It must look beyond a discovery-to-control paradigm for emergent diseases, to a research-to-prevention-to-discovery-to-control paradigm. Within these mechanisms of governance lay the difficult tasks of regulating capital in its excesses. This- to repeat my earlier point - was the basic issue in the development of national economies, and it is of necessity the basic issue in the creation of global governance. To succeed, these issues must enter the discourses of global governance in a direct way (and not be viewed as some exotic side issue). I conclude by repeating a portion of the previous quote from Nayyar and Court. Global governance means:

"This would mean providing global public goods, such as world peace and a sustainable environment, as well as regulating global public bads, such as international crime whether trade in drugs, arms, people, or [human] organs. It will be necessary to reform existing institutions and to introduce new rules or create new institutions. Some of these would require a system to correct for the failures of unregulated or liberalized international markets..."

${ }^{9}$ An especially egregious instance exists in China, in which hundreds of thousands, perhaps millions of peasants moving into cities have over the past decade been employed in myriad construction projects, including many proceeding under the approval of government authority. A current suit is being conducted on behalf of these workers who are owed \$42 BILLION in unpaid wages. This is a country in which annual individual income is still a pittance. It is no secret who benefits and who loses from such a situation (18).

${ }^{10}$ The next great crisis in globalization has already begun to emerge. As capacity spread through out the developing world for labor-cheap manufacturing, countries such as Bangladesh became early players in the inexpensive manufacture of world goods. The rapid integration of China and India with their enormous labor forces into world markets is threatening to overwhelm other countries in this role, creating capital movement and resulting unemployment and deepening poverty. One adds to this the opening wedge of service industry outsourcing from the developed word, from low level work, e.g. call centers, to the highest levels of professional training. Radiologists in the United States (average income north of $\$ 300,000$ ) may be replaced by those in India (average income of around $\$ 25,000$ ); similar issues exist in engineering, computer programming and medical technology. Singapore, acutely aware of the implications for this threat is investing heavily to upgrade the country's professional labor force to better gain niches in scientific and technological research. As the deputy minister for development told me some months ago, "we can make all the capacity we need to stay competitive; we rent brains. It is cheaper and more efficient." (The opportunity in question arose from the U.S. government's decision in 2002 not to pursue stem cell research.) In this view of research, only a portion of it needs to be site specific.

${ }^{11}$ This argument accords with the general thrust of Burci and Vignes in their recent review of WHO, in which they argue for a strong step beyond what they see as the legal timidity of the organization in the direction of a stronger "normative stance" (22).

\section{References}

(1) Neubauer D. Health care policy in the era of globalization, keynote address, Annual Meeting of the Public Health Association of New Zealand, Hamilton, N.Z. 1997; July 1-3.

( 2 ) Committee for the Study of the Future of Public Health. The Future of Public Health. Washington DC: National Academy Press; 1988.

( 3 ) Neubauer D, Pratt R. The second public health revolution: a critical appraisal. J Health Polit Policy Law. 1981;6:205-228.

( 4 ) Evans RG, Barer ML, Marmor TR. Why Are Some People Healthy and Others Not?: The Determinants of Health of Populations. New York: Aldine De Gruyter; 1994.

( 5 ) Murphy FA. Emerging Zoonoses. Emerg Infect Dis, Special Issue. 1998; July-September: 4 (3). Available from: URL: www.cdc.gov/ncidod/eid/vol4no3/childs.htm

( 6 ) Neubauer D. The Incredible Shrinking State. Social Alternatives. 1998;17:10-11.

( 7 ) Kotz DM. Neoliberalism and the reproduction of capitalism.

Paper presented to the Union for Radical Political Economics at the Allied Social Science Associations Convention, New York. 1999; 3-5 January.

( 8 ) Keating D, Hertzman C editors. Developmental Health and the Wealth of Nations. New York: Guilford Press; 1999.

(9) Stone D. Policy Paradox: The Art of Political Decision Making. New York: W. W. Norton \& Co.; 1997.

(10) Elliott C. Better than Well: American Medicine Meets the American Dream. New York: W.W. Norton; 2003.

(11) Edelman M. Political Language: Words that Succeed and Policies that Fail. New York: Academic Press; 1977.

(12) Martin E. The Woman in the Body: A Cultural Analysis of Reproduction. Boston: Beacon Press; 1992.

(13) Barnet RJ, Muller RE. Global Reach: The Power of Multinational Corporations. New York: Simon and Schuster; 1974.

(14) Nayyar D, Court J. Governing Globalization: Issues and Institutions. Policy Brief No. 5. New York: United Nations 
University; 2002.

(15) Harvey D. The Condition of Postmodernity. Oxford: Blackwell; 1990.

(16) Neubauer D. Assaying the Frontiers of Globalization: explorations in the New Economy. American Studies. 2000;41:1332.

(17) Castells M. The Information Age: Economy, Society and Culture, Vol. 1, The Rise of the Network Society, 2nd ed. Malden, MA: Blackwell; 2000.

(18) Neubauer D. Mixed blessings of the mega-cities. 2004; 24 September. Available from: URL: http:yaleglobal.yale.edu

(19) McNeill WH. Plagues and People. Garden City, NY: Anchor Press; 1976.
(20) Aksu E, Camilleri JA. Democratizing Global Governance. London: Palgrave; 2002.

(21) Young O. Global Governance: Drawing Insights from the Environmental Experience. Cambridge, MA: 0The MIT Press; 1997.

(22) Burci GL, Vignes C. World Health Organization. The Hague: Kluwer Law International; 2004.

(23) World Health Organization. Emerging zoonoses. 2005. Available from: URL: www.who.int/zoonoses/emerging_zoonoses/ en/

(24) Douglas M. Risk Acceptability According to the Social Sciences. London: Routledge \& Kegan Paul; 1985. 